\title{
(Multi)LETRAMENTOS DIGITAIS NO ENSINO DE LÍNGUA INGLESA NO ENSINO MÉDIO TÉCNICO
}

Tiago Pellim*

Resumo: A globalização e as novas TICs têm modificado a maneira como construímos sentidos, gerando impactos para o ensino de línguas. Com base nos referenciais teóricos da pedagogia dos multiletramentos e dos letramentos digitais, este artigo apresenta um projeto desenvolvido com uma turma do $3^{\circ}$ ano do ensino médio técnico em química, no qual os alunos tiveram que mobilizar seus conhecimentos do curso técnico e das aulas de inglês para criar infográficos multimodais. O resultado evidencia a mobilização criativa e crítica de diferentes recursos semióticos no design dos textos.

Palavras-chave: Multiletramentos. Letramentos digitais. Ensino de línguas.

\section{Globalização, ComunicaÇÃo E ENSINo de líNGUAS NA SOCIEDADE DA INFORMAÇÃO}

"O fenômeno da globalização, se por um lado ainda carece de consenso quanto aos seus processos e consequências, por outro goza da certeza de que não pode mais ser negado. A ruptura de fronteiras (e, mais recentemente, a contrarreação de fechamento das mesmas) e o aumento do fluxo de informações e sujeitos potencializado pelas novas Tecnologias da Informação e Comunicação (TICs) necessariamente trazem impactos para a vida em sociedade, na medida em que aproximam culturas antes distantes, evidenciam diferenças até então escamoteadas e criam novos espaços de sociabilidade, mas também de desigualdade.

No bojo dos processos globalizadores, o avanço das novas TICs e da Web 2.0 evidencia transformações nos modos pelos quais produzimos sentidos por 
meio das práticas sociais cotidianas. Usuários deixam de ser meros consumidores para passarem a ser, também, em alguma medida, produtores de conteúdo semiótico que circula em escala cada vez mais global. Por essas razões, autores como Braga (2013) sugerem que vivemos hoje em uma sociedade da informação, na qual o domínio dos meios de informação e comunicação se constitui como "capital de troca". Nesse contexto, o acesso à informação passa a ser crucial para o exercício da cidadania. Esse acesso tem se dado, cada vez mais, através de meios digitais, o que levou a um aumento no número de gêneros e composições textuais que, por sua vez, configuram novas práticas comunicativas.

Pinheiro (2014) destaca, com base em Knobel e Lankshear (2007), que os modos de interação e produção de sentidos possibilitados pelas novas tecnologias mobilizam recursos semióticos, valores, técnicas e saberes distintos daqueles com os quais já estávamos familiarizados e que são privilegiados na escola. Surge daí a necessidade de submeter a uma revisão conceitual os aparatos teóricos que sempre orientaram as práticas de letramento escolar, com o objetivo de pensar em um novo letramento que seja responsivo às demandas de uma sociedade que é cada vez mais multicultural e multi (ou hiper) semiotizada.

Consideramos, portanto, que as transformações geradas pela globalização e, paralelamente, pelo surgimento das novas tecnologias da informação e da comunicação têm reconfigurado os modos pelos quais utilizamos a língua para construir sentidos e nos comunicarmos. Este cenário afeta diretamente o trabalho feito pelo professor de línguas (tanto materna como estrangeiras), de forma que não é mais possivel conceber seu ensino como simples sistematização de regras gramaticais, atividades descontextualizadas e memorização de vocabulário.

Tal problematização se mostra ainda mais complexa quando consideramos o contexto da educação técnica profissionalizante. Dentre as características da globalização discutidos por Burbules e Torres (2000), a reestruturação das relações de mercado e trabalho tem, entre outras coisas, mudado a maneira como entendemos a atividade profissional na sociedade contemporânea, de forma que a própria ideia de formação para o "mercado do trabalho" precisa ser repensada.

Procurando dar conta da complexidade do uso da lingua na contemporaneidade, este artigo parte do conceito de multiletramentos para discutir o trabalho com letramentos digitais na aula de língua inglesa de uma turma de ensino médio técnico, como uma tentativa de alcançar o que Cavalcanti (2013) chama de "educação linguística ampliada", isto é, um ensino linguístico que vai além do conhecimento sistêmico sobre a língua alvo, incorporando uma visão ativa e refletida sobre o uso da língua no cenário hiper-semiotizado descrito aqui.

\section{A Pedagogia dos multiletramentos}

O panorama traçado na seção anterior é importante porque, segundo autores como Morgan e Ramanathan (2013), Luke (2014) e Janks (2014), a necessidade de novas práticas de letramento na escola tem de ser pensada justamente tendo como pano de fundo o contexto de grande diversidade e fluxo de informações potencializado pelos processos globalizadores. 
Morgan e Ramanathan (2013) argumentam que o fenômeno da globalização acaba impondo a necessidade de repensar os domínios do trabalho, da educação e da vida pública, tendo em vista os sistemas de informação global, como a internet, e as novas habilidades digitais que tais sistemas requerem dos usuários. Para fazer frente a esse cenário, seria preciso desenvolver

[...] noções plurais de letramentos e multiletramentos para ajudar os alunos a negociar uma maior variedade de tipos de texto e modos de persuasão, não apenas na modalidade impressa, mas também através de sons, imagens, gestos, espaços e sua integração multimodal (MORGAN; RAMANATHAN, 2013, p. 188).

Procurando dar conta desse desafio, um grupo de pesquisadores sobre letramentos de diferentes países uniu-se para publicar, em 1996, o manifesto intitulado A pedagogy of multiliteracies: designing social futures. Esse grupo de pesquisadores ficou conhecido como New London Group (NLG). Já no título desse trabalho, duas palavras resumem alguns dos conceitos-chave que orientariam as discussões sobre letramento escolar na contemporaneidade. São elas: multiletramentos e design.

A pedagogia dos multiletramentos parte de um entendimento de lingua e, portanto, de letramento, como algo que vai muito além da mera codificação e decodificação de signos, visão essa bastante comum no que Monte Mór (2015) classifica como a "primeira geração" dos estudos sobre letramento. As mudanças na sociedade, potencializadas pela globalização no final do século XX e a multiplicidade de canais de comunicação aliada ao aumento da diversidade cultural, aponta para o descompasso entre o que fazemos na escola e os modos pelos quais nossos estudantes se comunicam e interagem nas redes. Daí a urgência de uma visão mais ampla do que entendemos por letramento, de forma a envolver as diferenças culturais e linguísticas que estão mais evidentes do que nunca.

Nesse sentido, o manifesto publicado pelo NLG em 1996 tenta responder a dois aspectos já emergentes à época: a diversidade cultural e a multiplicidade dos meios de comunicação, ambos evidenciados e potencializados pelo avanço das novas tecnologias da informação e comunicação. Assim, o prefixo multi do termo multiletramentos assume um duplo sentido. Chama atenção tanto para o fator multicultural das sociedades, quanto para a natureza cada vez mais multimodal da comunicação no mundo contemporâneo. Em relação a esse segundo aspecto, o foco dos multiletramentos passa a ser em como os sujeitos constituem sentido por meio da articulação entre a língua e outros modos ou recursos semióticos. Passa-se a construir um entendimento de que os sentidos concebidos com base em diferentes recursos semióticos não devem ser vistos de forma estanque. Tais recursos se relacionam de maneiras complexas na produção de novos sentidos que não se resumem à simples soma de cada parte. Nessa linha, Lemke (2010) sugere que pensemos no caráter multiplicativo dos sentidos desenvolvidos a partir de diferentes linguagens e recursos.

$\mathrm{Na}$ tentativa de operacionalizar o trabalho na perspectiva dos multiletramentos são apresentados quatro componentes que integrariam essa proposta pedagógica. Os autores deixam claro, no entanto, que não se trata de um método fechado, ou de estágios que devam ser seguidos em uma lógica linear. Antes, faz 
mais sentido pensar em quatro "momentos" da prática pedagógica que se relacionam de maneira complexa e situada. Tais componentes são: prática situada, na qual os estudantes baseiam-se no que já lhes é familiar para relacioná-lo com o novo; instrução explícita, que se refere à construção de uma metalinguagem sobre o fenômeno estudado; enquadramento crítico, em que os estudantes devem relacionar conhecimento e prática às relações de poder que perpassam a sociedade; e prática transformada, na qual os estudantes recriam o que aprenderam de forma reflexiva e original.

Aqui entra em cena o segundo termo destacado anteriormente. O conceito de design sugere que nos processos de construção de sentido, precisamos partir, necessariamente, dos sentidos, padrões e convenções de que já dispomos na sociedade. Mas, ao mesmo tempo, a prática transformada aponta para a possibilidade de novos arranjos para além do que já está dado. Em outras palavras, o conceito de design convida-nos a pensar as práticas de letramento sem resvalar nem na ideia de simples reprodução ou cópia de sentidos já previamente definidos, nem de um total ineditismo. As produções dos estudantes podem ser vistas, nessa lógica, como rearranjos ou redesigns que partem do que já lhes é familiar para, sob um olhar crítico, criar novos sentidos em uma prática transformada. Este conceito está fortemente ligado ao aspecto multimodal da comunicação nos dias atuais e em como diferentes linguagens são mobilizadas pelos sujeitos para criar sentidos. Segundo Ribeiro (2016, p. 34),

[...] sempre que se precisa compor um texto, considerando-se aqui todas as linguagens que poderiam ser chamadas para essa composição, é importante pensar em seu design e na 'costura' entre linguagens e recursos (linguísticos, imagéticos, gráficos).

Para Kalantzis e Cope (2004), há duas condições necessárias para pensar a aprendizagem na perspectiva do design. A primeira delas seria fomentar um sentimento de pertença do aluno em relação ao contexto escolar em que ele está inserido e em relação ao conteúdo estudado. Esse ponto está, de certa maneira, ligado ao fato de que as práticas de letramento, vistas como formas de ação social, estão sempre inseridas em relações de poder. Já a segunda condição diz respeito à dimensão transformadora da educação, de modo que os processos de conhecimento deveriam levar o aluno a perceber-se como agente transformador do contexto em que está inserido.

Feito esse breve panorama do surgimento da pedagogia dos multiletramentos, é possivel perceber que há alguns desafios a serem enfrentados quando pensamos nessa proposta para o contexto brasileiro de ensino, em especial do ensino técnico profissionalizante, foco deste artigo. Primeiro, é preciso superar o falso dilema entre, por um lado, ensinar os conteúdos ou técnicas do currículo profissionalizante ou, por outro, envolver os alunos em práticas de multiletramento. O grande salto a ser dado é perceber justamente que não deveria haver aí uma dicotomia. O que se apresenta é a necessidade de pensarmos em formas de trabalhar os conteúdos curriculares da formação técnica, ao mesmo passo em que se fomenta uma cultura participativa/colaborativa e uma postura agentiva e crítica por parte dos alunos.

Outro ponto fundamental está relacionado à necessidade de repensarmos o papel e o formato da produção dos alunos em sala de aula se queremos avançar 
em uma perspectiva de letramento que favoreça o processo criativo e colaborativo de construção de sentidos. Para tanto, os letramentos digitais podem acenar com a potencialidade de inter-relacionar diferentes conhecimentos, ao mesmo tempo que prepara os alunos para um mundo marcado pelos avanços tecnológicos. É sobre tais avanços que discutiremos na próxima sessão.

\section{LETRAMENTOS DIGITAIS}

A sociedade da informação, mencionada por Braga (2013) e discutida anteriormente, tem gerado mudanças nas práticas comunicativas, propiciando novas formas de construção e compartilhamento do conhecimento que apontam, por sua vez, para novos letramentos. Dentre estes, destacam-se os letramentos digitais, que demandam, como aponta a autora citada, mais que simplesmente aprender a executar operações de comandos no computador. O que se ressalta aqui é que há mudanças significativas nos modos como lemos e produzimos textos impulsionadas pela própria natureza do meio digital. Nessa mesma linha, Goulart (2017, p. 53) afirma que "novas condições de produção determinam novas formas de organização do discurso, novos gêneros, novos modos de ler e de escrever", o que vai além das práticas tradicionais de letramento baseadas no meio impresso.

Dudeney, Hockly e Pegrum (2016, p. 17) assim definem os letramentos digitais: "habilidades individuais e sociais necessárias para interpretar, compartilhar e criar sentido eficazmente no âmbito crescente dos canais de comunicação digital". Note-se que o trabalho com os letramentos digitais não se reduz a ensinar a usar o computador ou executar comandos básicos. Antes, trata-se de desenvolver com os alunos habilidades que os auxiliem a buscar, selecionar, interpretar e produzir conteúdo de forma crítica e criativa na sociedade da informação. Braga (2013, p. 62) elenca três habilidades estratégicas que devem permear o trabalho com os letramentos digitais: “(i) estratégias de busca de informação e de critérios de seleção, (ii) competências para integração de conhecimentos de áreas diversas, e (iii) senso crítico para saber avaliar as consequências sociais de suas escolhas".

A internet assume então a centralidade dos processos de busca e produção de conhecimento e está diretamente ligada à importância dos letramentos digitais nas escolas. Segundo Braga (2013, p. 15), o desenvolvimento de letramentos digitais em atividades pedagógicas torna-se fundamental no momento atual,

[...] no qual a internet, cada vez mais, ocupa um espaço social de destaque, seja como fonte de informação e/ou meio para a construção de conhecimentos, seja como espaço para manifestações culturais e interações sociais dos mais variados tipos.

Além disso, a internet tem outra implicação para o ensino de línguas, em específico de línguas estrangeiras (no meu caso, o inglês). Como nos lembra Braga (2013), em países continentais como o Brasil, os estudantes em geral têm poucas oportunidades de praticar os conhecimentos linguísticos trabalhados em sala de aula. Com a internet e a explosão de conteúdo multimídia ao qual temos acesso nas redes sociais, aprendizes podem vivenciar o que a autora cha- 
ma de "imersão linguística virtual", de forma que a língua estrangeira, que antes era vista como algo distante, agora passa a estar presente em jogos, séries, memes, fóruns etc. Essa situação muda um pouco a visão do inglês como língua estrangeira distante, utilizada apenas em viagens ao exterior, tornando-a cada vez mais presente no nosso cotidiano.

O uso das novas tecnologias em sala de aula atende, cabe dizer, a imperativos externos e internos. Como explicam Dudeney, Hockly e Pegrum (2016), os imperativos externos dizem respeito à necessidade de preparar nossos alunos para atuarem em um mundo cada vez mais digital. Já os internos referem-se aos beneficios que o uso das tecnologias pode trazer para o próprio processo de ensino/aprendizagem em sala de aula. Para esses autores, os letramentos digitais estão, portanto, vinculados a ambos imperativos: "são habilidades essenciais que nossos alunos precisam adquirir para sua plena participação no mundo além da sala de aula, mas também podem enriquecer sua aprendizagem em sala de aula" (DUDENEY; HOCKLY; PEGRUM, 2016, p. 20).

Entretanto, para que as novas tecnologias realmente tragam uma mudança qualitativa para as práticas escolares, é necessário, como aponta Coscarelli (2017), refletir sobre que concepção de ensino/aprendizagem orienta essas práticas. Isso porque "o fato de usar a informática nas aulas não transforma instantaneamente o ensino em alguma coisa 'moderna' e 'eficiente" (COSCARELLI, 2017 , p. 26). Em outras palavras, simplesmente substituir o quadro negro por uma lousa digital, para continuar a projetar conteúdo que deverá ser copiado pelos alunos, não muda a prática pedagógica de forma substancial. De forma semelhante, substituir cadernos e livros fisicos por tablets e laptops, que serão utilizados apenas para leitura e digitação de conteúdo, não pode ser considerado letramento digital.

Procurando operacionalizar alguns dos conceitos e desafios discutidos aqui em uma sala de aula de língua inglesa, analiso agora uma proposta didática desenvolvida com alunos do $3^{\circ}$ ano do ensino médio técnico de uma instituição de educação técnica e tecnológica do interior de São Paulo.

\section{ProduÇÃo de INFOGRÁficos No ENSINO MÉdio TÉCNICO}

O que conta como um texto? Ribeiro (2016) nos lembra que os textos e suas características mudam ao longo da história, bem como os modos de escrita e leitura. Nesse sentido, se retomarmos a discussão sobre os impactos dos processos globalizadores e das novas TICs na comunicação na contemporaneidade, Dionísio (2011, p. 137) sugere a "necessidade da revisão, e ampliação, de alguns conceitos basilares no campo dos estudos das interações humanas e no âmbito dos estudos sobre processamento textual". Em outras palavras, a maneira como lemos e escrevemos textos têm mudado nos últimos tempos (mudanças promovidas, em grande parte, pelos avanços tecnológicos), e isso tem efeitos para o trabalho dos professores de linguas.

Nossos alunos passam cada vez mais tempo na frente de alguma tela (da TV, do computador ou do celular). Consequentemente, as práticas de leitura têm se dado cada vez mais por meio de textos digitais. A saída do papel para as telas não se configura, no entanto, como uma simples mudança de meio ou suporte. Os textos digitais abrem espaço para novas configurações textuais que incorpo- 
ram diferentes recursos semióticos (imagens, vídeos, sons, GIFs, hyperlinks etc.), exigindo novas práticas de letramento, fato esse já vislumbrado pelo NLD em 1996. Segundo Dionísio (2011, p. 138), "na atualidade, uma pessoa letrada deve ser alguém capaz de atribuir sentidos a mensagens oriundas de múltiplas fontes de linguagem, bem como ser capaz de produzir mensagens, incorporando múltiplas fontes de linguagem". A partir dai, o conceito de letramento passa por revisões a fim de ressaltar a multiplicidade de recursos empregados na construção de sentidos. Dionísio (2011) propõe, então, que seja melhor falar em letramentos, no plural, já que a multimodalidade passa a ser entendida como um traço constitutivo de toda prática discursiva.

Este artigo discute o trabalho pedagógico com um gênero marcadamente multimodal, a saber, o infográfico. Dionísio (2011, p. 146), com base em Harris e Lester (2002), explica que o infográfico "é uma das mais sofisticadas formas de explicar complexas histórias ou procedimentos, porque combina palavras e imagens, quando palavras apenas poderia ser cansativo para os leitores e a imagem apenas seria insuficiente”. Ribeiro (2016), por sua vez, destaca algumas características dos infográficos que fazem que esse seja um gênero textual relevante para ser trabalhado na aula de línguas. Primeiro, por se tratar de um "texto multimodal por excelência, já que seu planejamento já o constrói com, pelo menos, palavras e imagens em um leiaute" (RIBEIRO, 2016, p. 31). Segundo, porque esse gênero tem ganhado cada vez mais destaque na mídia, tanto impressa quanto televisiva e on-line. Em terceiro lugar, a construção de um infográfico requer um planejamento que envolve desde escolhas lexicais e imagéticas, até paleta de cores e disposição das informações na página. Finalmente, a autora nos questiona: Quem nos ensina a ler e produzir infográficos? Tal questionamento se dá a partir da observação de que os gêneros multimodais como infográficos, tabelas e mapas são comuns nas aulas de geografia e história, por exemplo, mas são pouco explorados nas aulas de línguas.

Neste artigo, defendo a hipótese de que os gêneros multimodais, quando abordados da perspectiva dos multiletramentos e dos letramentos digitais, oferecem a possibilidade de articulação entre o letramento em língua estrangeira (no meu caso, o inglês) e o conteúdo específico de cursos técnicos a partir de uma visão mais crítica e menos "instrumentalista". Além disso, podem proporcionar um uso mais significativo da lingua por fazê-lo por meio de textos com os quais os estudantes têm contato principalmente no mundo digital.

É com base nesses pressupostos que foi feita, aos alunos do $3^{\circ}$ ano do ensino médio técnico em Química, uma proposta de produção de infográficos nas aulas de língua inglesa com o seguinte tema: Chemistry in our daily lives (Química no dia a dia). A proposta tinha como objetivos: 1. promover uma integração entre o conteúdo da formação técnica e da disciplina de inglês; 2 . desenvolver as bases dos (multi)letramentos digitais; e 3. fomentar uma perspectiva crítica com relação à presença da química na nossa vida diária, em vez de uma disciplina puramente técnica e distante do cotidiano. Na tabela a seguir é possivel ver, de modo simplificado, os principais momentos do projeto e como eles se enquadram na proposta da pedagogia dos multiletramentos (NLG, 1996). 
Quadro 1 - O projeto didático

\begin{tabular}{|c|c|c|}
\hline Etapas do projeto & Atividades realizadas & $\begin{array}{c}\text { Pedagogia dos } \\
\text { multiletramentos }\end{array}$ \\
\hline \multirow[b]{2}{*}{$\begin{array}{c}\text { Exposição ao tema } \\
\text { e ao texto }\end{array}$} & $\begin{array}{l}\text { Reflexão sobre o que é a } \\
\text { química e como ela está } \\
\text { presente ao nosso redor }\end{array}$ & $\begin{array}{c}\text { Prática situada/ } \\
\text { enquadramento crítico }\end{array}$ \\
\hline & $\begin{array}{l}\text { Leitura e análise de } \\
\text { diferentes infográficos sobre } \\
\text { a química por trás de objetos } \\
\text { e alimentos comuns no } \\
\text { nosso dia a dia }\end{array}$ & $\begin{array}{c}\text { Prática situada/ } \\
\text { enquadramento crítico }\end{array}$ \\
\hline $\begin{array}{c}\text { Análise das condições de } \\
\text { leitura e produção } \\
\text { textual }\end{array}$ & $\begin{array}{l}\text { Análise dos textos guiada } \\
\text { por perguntas como: Quem } \\
\text { escreveu? Com que objetivo? } \\
\text { De que forma? Para quem? }\end{array}$ & $\begin{array}{c}\text { Instrução aberta/ } \\
\text { enquadramento crítico }\end{array}$ \\
\hline Geração de ideias & $\begin{array}{l}\text { Definição dos grupos e dos } \\
\text { temas dos infográficos } \\
\text { e definição de conteúdo }\end{array}$ & Enquadramento crítico \\
\hline \multirow{2}{*}{ Produção ou criação } & $\begin{array}{l}\text { Criação dos infográficos } \\
\text { utilizando diferentes } \\
\text { plataformas digitais } \\
\text { (Canva, Visme, Easel.ly) }\end{array}$ & $\begin{array}{l}\text { Prática transformada/ } \\
\text { enquadramento crítico }\end{array}$ \\
\hline & $\begin{array}{l}\text { Revisão dos infográficos: } \\
\text { revisão linguística, visual } \\
\text { (layout), de conteúdo etc. }\end{array}$ & $\begin{array}{l}\text { Prática transformada/ } \\
\text { enquadramento crítico }\end{array}$ \\
\hline $\begin{array}{l}\text { Apresentação } \\
\text { e discussão }\end{array}$ & $\begin{array}{c}\text { Apresentação dos } \\
\text { infográficos e avaliação } \\
\text { do professor e dos alunos }\end{array}$ & $\begin{array}{c}\text { Prática situada/ } \\
\text { enquadramento crítico }\end{array}$ \\
\hline
\end{tabular}

Foge ao escopo deste artigo uma descrição detalhada de cada uma das atividades desenvolvidas em sala de aula. No entanto, alguns pontos merecem destaque. Note-se que partimos da área de formação técnica dos alunos (Química) para propor uma reflexão sobre como esse conhecimento técnico pode ser utilizado para compreender, de forma mais aprofundada, a vida cotidiana e como, enquanto futuros Técnicos em Química, esses estudantes podem intervir no mundo. Esse tipo de reflexão está ligado ao conceito de design de Kalantzis e Cope (2004) discutido anteriormente e que prevê que os estudantes precisam se relacionar com o conteúdo trabalhado, percebendo-se como agentes de transformação do mundo.

Outro ponto a ser destacado é a presença de uma visão crítica (enquadramento crítico, na nomenclatura da pedagogia dos multiletramentos) durante 
todo o projeto. Justifico esse aspecto por entender que o olhar crítico deve permear o processo como um todo, não ficando estanque a uma etapa específica ou a uma aula. Entendo que há momentos em sala de aula em que a reflexão crítica se dá de forma mais explícita. No entanto, reafirmo minha leitura de que o pensamento crítico não deve ser resumido a uma atividade ou visto como um produto final a ser alcançado no fim do bimestre, mas como um princípio que deve ser exercitado constantemente e que deve orientar toda prática pedagógica.

Analisaremos, agora, algumas produções dos alunos. Para tanto, vou me embasar nas cinco ações de design mencionadas por Dias (2012) e que compõem qualquer projeto básico de editoração. São eles: 1. organização da página; 2. efeitos tipológicos (envolvem escolha de fontes, cores etc.); 3. recursos gráficos (tabelas, quadros etc.); 4. efeitos visuais (mapas, imagens, diagramas etc.); 5. organizadores de texto (títulos, subtítulos, legendas, cabeçalhos, rodapés etc.). Além dessas cinco dimensões do design, quero olhar também para o próprio conteúdo informacional dos infográficos.

No primeiro infográfico (The chemistry of coffee), percebe-se que os alunos optaram por uma organização mais linear da página. Destaco a escolha da paleta de cores, da imagem de fundo no título do infográfico, dos pequenos grãos de café que acompanham os subtítulos, da representação visual dos compostos químicos e das xícaras no fim da página com elementos químicos, como escolhas inteligentes e criativas de recursos tipológicos e de efeitos visuais que atuam diretamente na construção de sentidos do texto. Retomando Lemke (2010), este é um bom exemplo de que como elementos visuais e verbais atuam em uma lógica multiplicativa, isto é, os sentidos incorporados ao texto por meio dos recursos visuais e verbais multiplicam-se para construir o sentido global do infográfico. Com relação aos organizadores de texto, note-se que os subtítulos organizam o infográfico a partir do que foi anunciado na introdução: "Let's explore its chemistry composition". A partir daí, seguem-se explicações sobre a cafeína, o ácido clorogênico e a niacina. Em se tratando do conteúdo informacional do infográfico, é possivel perceber que o grupo optou por explorar a composição química do café, selecionando seus principais compostos e mencionando os efeitos de cada um deles no organismo.

No segundo infográfico (Chemistry of soda), a organização da página é menos linear, permitindo diferentes percursos de leitura. Há uma pequena introdução logo abaixo do título do infográfico, a qual é seguida por seis subtitulos que abordam desde os maiores produtores e consumidores de refrigerante no mundo, a importância do gás na bebida, passando pelos principais componentes, até a relação entre consumo de refrigerante e obesidade, evidenciando um olhar crítico sobre o conteúdo do material. Com relação aos elementos visuais, há uma composição que mistura fotografias e desenhos e que assumem, neste infográfico, uma função mais ilustrativa. No entanto, há ainda a representação visual dos acidulantes e conservantes que não se limita a uma função ilustrativa, mas fornece novas informações técnicas para o texto. 
Figura 1 - Infográfico The Chemistry Figura 2 - Infográfico Chemistry of Soda of Coffee
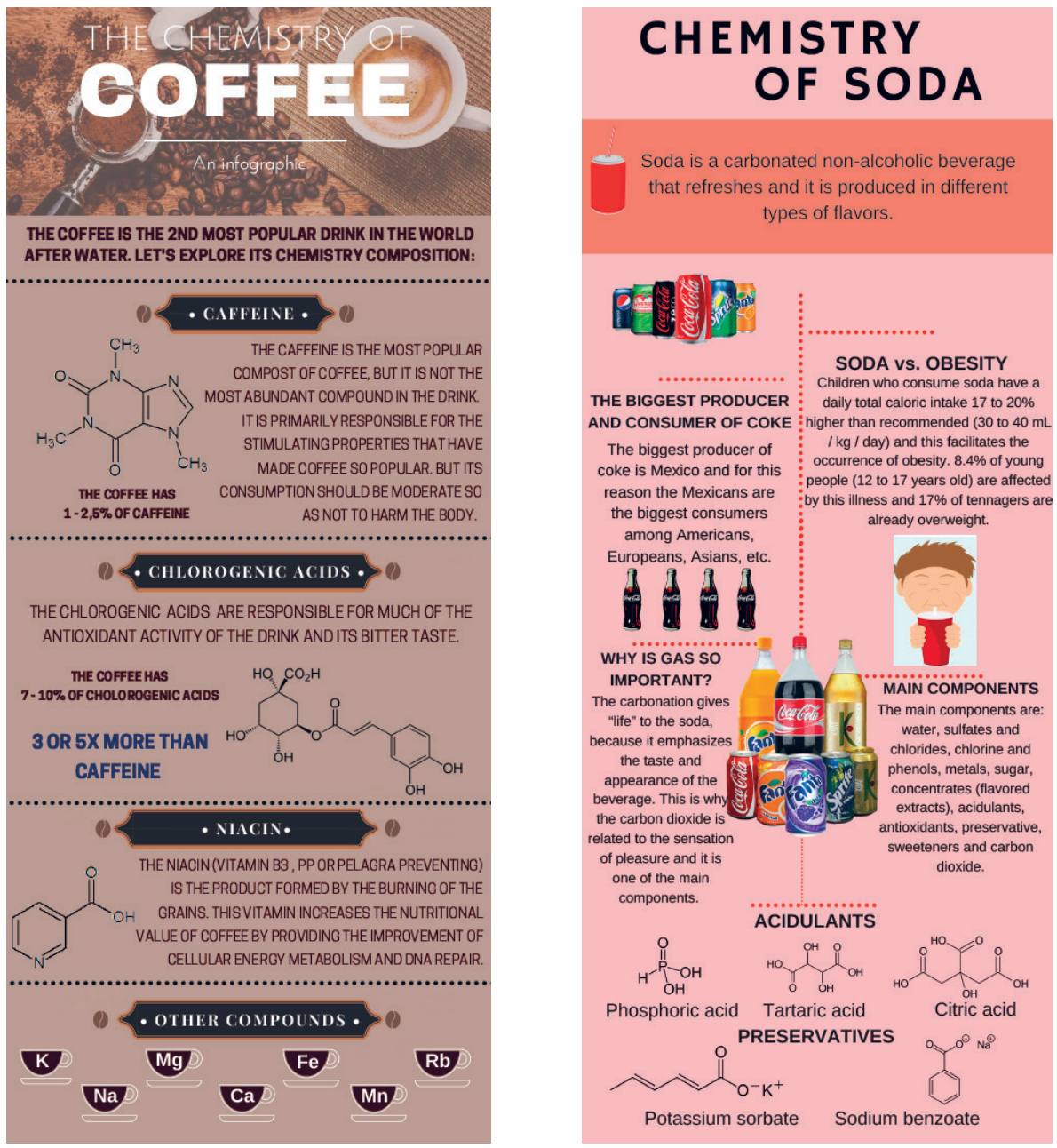

Em ambos os exemplos, pode-se observar que a produção do infográfico exigiu uma série de escolhas por parte dos alunos, desde a definição do tema e de que informações poderiam ser incluídas nesse gênero textual, passando pela seleção da paleta de cores e das imagens, até em como todos esses elementos seriam dispostos visualmente. Estas escolhas, quero deixar claro, não foram feitas de forma aleatória. Pelo contrário, são fruto de uma reflexão crítica orientada pelos questionamentos lançados na etapa de análise das condições de leitura e produção textual, que resultaram em um redesign, uma prática transformada na qual os estudantes puderam articular o conteúdo das aulas de língua inglesa aos seus conhecimentos técnicos de forma criativa.

Destaco que durante a realização do projeto, foram trabalhadas as habilidades estratégicas ligadas ao letramento digital e mencionadas anteriormente por 
Dudeney, Hockly e Pegrum (2016) e por Braga (2013), a saber: definição de estratégias de busca e critérios de seleção de informações; habilidade para integração de conhecimento e produção de conteúdo criativo; e desenvolvimento de senso crítico a fim de avaliar as implicações de cada escolha feita durante o processo criativo.

\section{CONSIDERAÇõES FINAIS}

Ensinar inglês talvez nunca tenha sido tão necessário e tão complexo. A demanda por conhecimento dessa lingua cresce cada vez mais não apenas para fins profissionais, mas igualmente para o acesso à informação e ao conhecimento, elementos vitais na sociedade da informação mencionada por Braga (2013). A globalização e as novas TICs estão profundamente imbricadas nessa sociedade, não sendo mais possível pensar no ensino de inglês sem considerar os avanços tecnológicos e suas implicações nas maneiras como utilizamos a língua para construir sentido e nos comunicar. Neste cenário, é comum que os professores se sintam sobrecarregados frente a tantas demandas: trabalhar com multiletramentos, diferentes gêneros textuais e multimodais, letramento digital, letramento crítico e, ainda por cima, ensinar a língua em si. A verdade é que não há resposta fácil para esse dilema. Cada professor, em cada contexto, precisa avaliar as necessidades e potencialidades de suas turmas a fim de definir os projetos pedagógicos mais interessantes a serem desenvolvidos.

Neste artigo, abordei brevemente os princípios teórico-metodológicos da pedagogia dos multiletramentos e dos letramentos digitais para apresentar uma amostra dos resultados de um trabalho desenvolvido com alunos do $3^{\circ}$ ano do ensino médio técnico em Química. Meu desafio com essa turma era tentar articular a lingua inglesa com os conhecimentos da área de formação técnica desses estudantes. Para tanto, propus a criação de infográficos com o tema "Química no dia a dia" embasado em uma série de motivos: esse tipo de texto exigiria um trabalho de composição entre diferentes semioses, exercitando o conceito de design da pedagogia dos multiletramentos (NLG, 1996); exigiria o trabalho com plataformas digitais on-line de criação gráfica, desenvolvendo as bases do letramento digital; levaria os estudantes a acionarem os conhecimentos específicos do curso técnico e refletirem sobre como esses conhecimentos agem no mundo à nossa volta; além de fazer com que os alunos utilizassem a lingua inglesa de maneira significativa.

Um dos principais efeitos do projeto foi auxiliar os estudantes a perceber os processos envolvidos na construção de sentido no meio digital através de textos cada vez mais multissemióticos. Como afirma Dionísio (2011, p. 149),

[...] é necessário que professores e alunos estejam plenamente conscientes de tais aspectos: o que eles são, para que eles são usados, que recursos empregam, como eles podem ser integrados um ao outro, como eles são tipicamente formatados, quais seus valores e limitações.

Esse tipo de conhecimento se mostra relevante na medida em que os jovens deixam cada vez mais de ser meros consumidores e passam a ser produtores de conteúdo. Como bem nos lembra Ribeiro (2016, p. 35), “em tempos de participa- 
ção, de 'web 2.0' e de 'faça você mesmo', é interessante que o não profissional conheça as ferramentas e as técnicas de que dispõe para compor mensagens e discursos na forma de textos multimodais".

O trabalho com ferramentas digitais em sala de aula pode assustar alguns professores que não se consideram muito familiarizados com essas tecnologias. No entanto, não é preciso ser um especialista em informática. Primeiro é preciso saber o que está disponível e como isso pode ser utilizado com fins didáticos. De acordo com Braga (2013, p. 21), "para introduzir a tecnologia digital em práticas de ensino, o professor precisa saber que tais recursos existem, definir quais ele precisa e onde e como ele pode procurá-los". Além disso, ciente das limitações materiais de muitas escolas, Coscarelli (2017) nos lembra que trabalhar com letramento digital não significa que os alunos precisam estar em um laboratório de informática o tempo todo. Muitas atividades que compõem um projeto maior podem ser realizadas sem o uso do computador.

Por fim, cabe reafirmar que o trabalho com (multi)letramentos digitais precisa ser acompanhado de uma postura questionadora a fim de que seja um diferencial na formação dos alunos, favorecendo uma reflexão de fato sobre os processos de construção de sentido na contemporaneidade. Para tanto, Ribeiro (2017, p. 90) afirma que, no uso das novas tecnologias, deve "prevalecer uma atitude ativa, reflexiva e construtiva sobre o conhecimento escolar, não favorecendo que o Word substitua o lápis e a tela do computador, a folha de papel". No entanto, se impregnada de uma visão crítica, a incorporação da tecnologia nas salas de aula pode nos ajudar a compreender melhor o mundo e como fazemos parte dele.

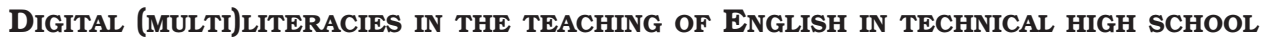

Abstract: Globalization and the new ICTs have changed the way we make meaning, therefore impacting the teaching of languages. Based on the theoretical references of the pedagogy of multiliteracies and digital literacies, this article presents a project implemented with a class of senior technical high school in chemistry in which students had to use their knowledge from both the technical course and the English classes in order to create multimodal infographics. The result shows the creative and critical use of different semiotic resources in the design of the texts.

Keywords: Multiliteracies. Digital literacies. Language teaching.

\section{REFERÊNCIAS}

BRAGA, D. Ambientes digitais: reflexões teóricas e práticas. São Paulo: Cortez, 2013.

BURBULES, N. C.; TORRES, C. A. Globalization and education: an introduction. In: BURBULES, N. C.; TORRES, C. A. (org.). Globalization and education: critical perspectives. New York: Routledge, 2000. p. 1-26. 
CAVALCANTI, M. C. Educação linguística na formação de professores de línguas: intercompreensão e práticas translíngues. In: MOITA LOPES, L. P. (org.). Linguística aplicada na modernidade recente: Festschrift para Antonieta Celani. São Paulo: Parábola, 2013. p. 211-226.

COSCARELLI, C. V. Alfabetização e letramento digital. In: COSCARELLI, C. V.; RIBEIRO, A. E. (org.). Letramento digital: aspectos sociais e possibilidades pedagógicas. 3. ed. Belo Horizonte: Ceale, Autêntica, 2017. p. 25-40.

DIAS, R. Gêneros digitais e multimodalidade: oportunidades on-line para a escrita e a produção oral em inglês no contexto da educação básica. In: DIAS, R.; DELL'ISOLA, R. L. P. (org.). Gêneros textuais: teoria e prática de ensino em LE. Campinas: Mercado de Letras, 2012. p. 295-315.

DIONÍSIO, A. P. Gêneros textuais e multimodalidade. In: KARWOSKI, A. M.; GAYDECZKA, B.; BRITO, K. S. (org.). Gêneros textuais: reflexões e ensino. São Paulo: Parábola, 2011. p. 137-152.

DUDENEY, G.; HOCKLY, N.; PEGRUM, M. Letramentos digitais. São Paulo: Parábola, 2016.

GOULART, C. Letramento e novas tecnologias: questões para a prática pedagógica. In: COSCARELLI, C. V.; RIBEIRO, A. E. (org.). Letramento digital: aspectos sociais e possibilidades pedagógicas. 3. ed. Belo Horizonte: Ceale, Autêntica, 2017. p. 41-58.

HARRIS, C. R.; LESTER, P. M. Visual journalism: a guide for new media professionals. Boston: Allyn \& Bacon, 2002.

JANKS, H. The importance of critical literacy. In: PANDYA, J. Z.; ÁVILA, J. Moving critical literacies forward: a new look at praxis across contexts. New York: Routledge, 2014. p. 32-44.

KALANTZIS, M.; COPE, B. Designs for learning. E-learning, v. 1, n. 1, p. 38-93, 2004.

KNOBEL, M.; LANKSHEAR, C. A new literacies sampler. New York: Peter Lang Publishing, 2007.

LEMKE, J. L. Letramento midiático: transformando significados e mídias. Trabalhos de Linguística Aplicada, Campinas, v. 49, n. 2, p. 455-479, 2010.

LUKE, A. Defining critical literacy. In: PANDYA, J. Z.; ÁVILA, J. Moving critical literacies forward: a new look at praxis across contexts. New York: Routledge, 2014. p. 19-31.

MONTE MÓR, V. Learning by design: reconstructing knowledge processes in teaching and learning practices. In: COPE, B.; KALANTZIS, M. (org.). A pedagogy of multiliteracies: learning by design. New York: Palgrave Macmillan, 2015. p. 186-209.

MORGAN, B.; RAMANATHAN, V. Critical literacies in language education: distancing ourselves from dominant texts and discourse. In: ROCHA, C. H.; MACIEL, R. F. (org.). Língua estrangeira e formação cidadã: por entre discursos e práticas. Campinas: Pontes, 2013. p. 187-215.

NEW LONDON GROUP. A pedagogy of multiliteracies: designing social futures. Harvard Educational Review, v. 66, n. 1, p. 1-27, 1996. 
PINHEIRO, P. A. A era do "multissinóptico": que (novos) letramentos estão em jogo? Educação em Revista, Belo Horizonte, v. 30, n. 2, p. 137-160, 2014.

RIBEIRO, A. E. Textos multimodais: leitura e produção. São Paulo: Parábola, 2016.

RIBEIRO, O. J. Educação e novas tecnologias: um olhar para além da técnica. In: COSCARELLI, C. V.; RIBEIRO, A. E. (org.). Letramento digital: aspectos sociais e possibilidades pedagógicas. 3. ed. Belo Horizonte: Ceale, Autêntica, 2017. p. 85-98.

Recebido em 16 de novembro de 2018.

Aprovado em 6 de fevereiro de 2019. 